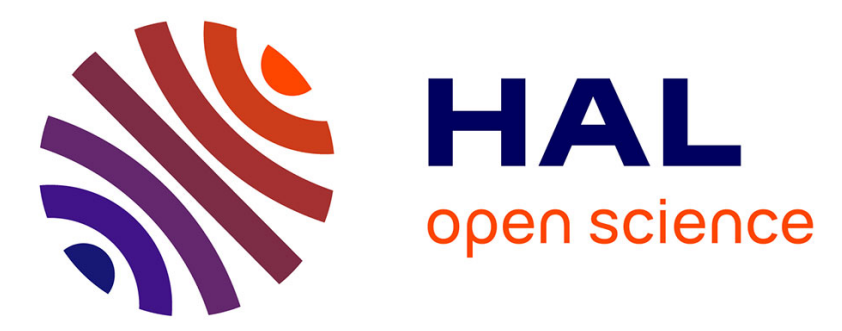

\title{
Screening for Fabry disease in male patients with end-stage renal disease in western France
}

\author{
C Vigneau, D P Germain, D Larmet, F Jabbour, M Hourmant
}

\section{To cite this version:}

C Vigneau, D P Germain, D Larmet, F Jabbour, M Hourmant. Screening for Fabry disease in male patients with end-stage renal disease in western France. Néphrologie \& Thérapeutique, 2021, 17 (3), pp.180-184. 10.1016/j.nephro.2021.03.002 . hal-03253737

\section{HAL Id: hal-03253737 \\ https://hal.science/hal-03253737}

Submitted on 15 Jun 2021

HAL is a multi-disciplinary open access archive for the deposit and dissemination of scientific research documents, whether they are published or not. The documents may come from teaching and research institutions in France or abroad, or from public or private research centers.
L'archive ouverte pluridisciplinaire HAL, est destinée au dépôt et à la diffusion de documents scientifiques de niveau recherche, publiés ou non, émanant des établissements d'enseignement et de recherche français ou étrangers, des laboratoires publics ou privés. 


\title{
Screening for Fabry Disease in Male Patients with End Stage Renal Disease in Western France
}

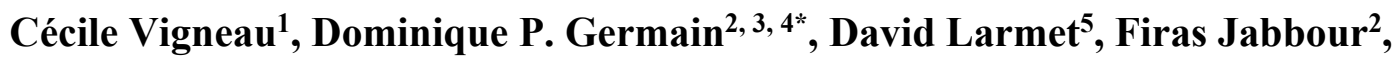 \\ Maryvonne Hourmant ${ }^{5}$ for the SNOUFY Investigators Group
}

1 University of Rennes, CHU Rennes, Inserm, EHESP, IRSET, UMR_S 1085, 35000 Rennes, France.

2 University of Versailles, French Referral Center for Fabry disease, Division of Medical Genetics, AP-HP Paris Saclay University, Garches, France.

3 Charles University, Second Department of Internal Medicine, First Faculty of Medicine, Prague, Czech Republic.

4 University of Puthisastra, Faculty of Medicine, Phnom Penh, Cambodia.

5 University of Nantes, Department of Nephrology, 44093 Nantes cedex 01, France.

\footnotetext{
* Corresponding author: Division of Medical Genetics, University of Versailles, Paris-Saclay University, 2 avenue de la source de la Bièvre, 78180 Montigny. France.

dominique.germain@uvsq.fr
} 


\begin{abstract}
Context: Fabry disease (FD) is a rare X-linked genetic disease due to pathogenic variants in the GLA gene. Classic FD is characterized by glycosphingolipids accumulation in all organs including the kidney, resulting in end-stage renal disease (ESRD) in a subset of male patients. FD should therefore be considered in the differential of patients with unexplained ESRD.
\end{abstract}

Objective: We performed a prospective screening study in Western France to determine the prevalence of FD in a large population of dialyzed and transplanted patients.

Patients and methods: Patients meeting the inclusion criteria (males, 18-70 years with ESRD of unknown or vascular origin) were selected from the REIN ${ }^{\circledR}$ registry and the CRISTAL $^{\circledR}$ database. Screening on filter papers was performed after patient consent was obtained during either a dialysis session or a transplantation follow-up visit.

Results: One thousand five hundred and sixty-one ESRD male patients were screened and 819 consented (dialysis: $n=242$, transplant: $n=577$ ). One single patient was found with decreased alpha-galactosidase levels $<25 \%$. GLA sequencing identified the p.Phe113Leu variant in favor of an unknown superimposed kidney disease responsible for ESRD since this GLA pathogenic variant is associated with a later-onset cardiac form of FD with minimal kidney involvement. Family cascade genotyping revealed a previously undiagnosed affected brother.

Conclusion: The prevalence of FD in ESRD patients was $0.12 \%$, questioning the efficacy of this screening strategy with respect to the low prevalence. However, beside the benefit for the patient and family, the increased awareness of FD among participating nephrologists may be of interest for future patients.

Key words: Fabry disease, end-stage renal disease, dialysis, transplantation, dried blood spot

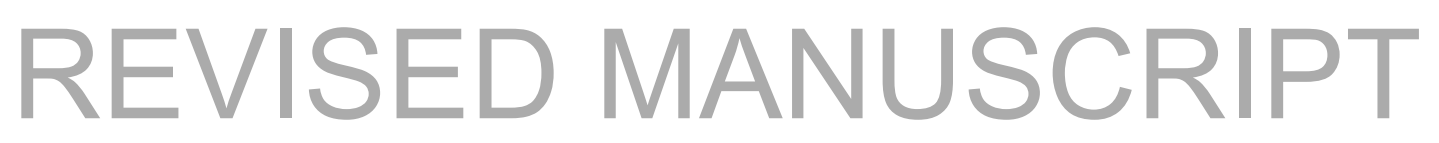




\section{Dépistage de la maladie de Fabry chez les hommes en insuffisance rénale chronique terminale dans l'Ouest de la France.}

Contexte : La maladie de Fabry (MF) est une maladie génétique, liée à l'X, due à la présence d'un variant pathogène du gène GLA. Elle est caractérisée par l'accumulation de glycosphingolipides dans le cœur, le système nerveux central et les reins, entrainant une insuffisance rénale chronique (IRC) terminale chez un pourcentage significatif de patients de sexe masculin et quelques femmes hétérozygotes. La MF doit être envisagée dans le diagnostic différentiel des insuffisances rénales terminales d'étiologie indéterminée.

Objectif : Nous avons réalisé une étude de dépistage prospective dans l'Ouest de la France afin de préciser la prévalence de la maladie de Fabry chez les hommes en dialyse ou porteurs d'une greffe rénale.

Patients et méthodes : Les patients remplissant les critères d'inclusion (sujets masculins, âgés de 18 à 70 ans, atteints d'une IRC terminale, de cause vasculaire ou inconnue) furent sélectionnés à partir du registre $\operatorname{REIN}^{\circledR}$ et de la base CRISTAL $^{\circledR}$. Le dépistage par dosage enzymatique fut réalisé sur papier buvard, après accord du patient obtenu lors d'une séance de dialyse ou une consultation de suivi de transplantation.

Résultats : Mille cinq cent soixante et un patients de sexe masculin en IRCT étaient éligibles et 819 furent testés (242 dialysés et 577 transplantés). Un seul patient fut dépisté (activité alphagalactosidase sur goutte de sang séché $<25 \%$ des valeurs normales). L'identification par séquençage du gène GLA du variant pathogène p.Phe113Leu est en faveur de l'existence d'une deuxième néphropathie puisque ce variant est habituellement associé à une forme cardiaque tardive de la maladie de Fabry avec une atteinte rénale absente ou mineure. L'enquête familiale a permis d'identifier un frère atteint.

\section{REVISED MANUSCRIPT}


Conclusion : La prévalence de la maladie de Fabry chez les patients en insuffisance rénale était de $0,12 \%$ interrogeant sur l'efficacité de la stratégie de dépistage. Cependant, outre le bénéfice direct pour le patient dépisté et sa famille, une meilleure connaissance de la maladie de Fabry parmi les néphrologues participants pourra être d'intérêt pour leurs futurs patients.

Mots-clés : Maladie de Fabry, insuffisance rénale chronique terminale, dialyse, transplantation, gouttes de sang séché. 


\section{Introduction}

Fabry disease (FD, OMIM \#301500) is a rare X-linked genetic disease due to pathogenic variants in the $G L A$ gene coding for the lysosomal $\alpha$-galactosidase $\mathrm{A}[1,2,3]$. FD is characterized by glycosphingolipids accumulation [4] in renal glomerular, tubular and vascular cells, leading to end-stage renal disease (ESRD) in a subset of male and, more rarely, female patients. There is a cardiac and central nervous system component with a hypertrophic cardiomyopathy with malignant arrhythmia and strokes [5-7].

Prevalence of the classic form of the disease has been estimated to be 1 in 50000 in the general population but screening studies in newborns and high-risk populations have revealed unexpected high frequencies $[8,9]$. Prevalence in cohorts of ESRD patients were historically found from 0 to $1.1 \%$ in dialyzed patients and from 0.2 to $0.4 \%$ in transplanted patients [10, 11] but a recent review compiling all 63 studies available to date was more in favor of a rate of $0.15 \%[12]$.

In Western France, the prevalence of Fabry disease is unknown, especially in ESRD patients. The objective of the study was to screen for FD, using an enzymatic assay on dried blood spot (DBS) [13] in a large population of dialyzed or transplanted male subjects.

\section{Patients and Methods}

SNOUFY (Société de Néphrologie de l'OUest maladie de FabrY) was a cross-sectional study that involved most of the nephrology centers of the four regions of Western France: Bretagne, Centre, Pays de la Loire and Poitou-Charentes, accounting for over 11 million inhabitants (Figure 1).

\section{Patients}


Patients were included according to the following criteria: males, aged 18 to 70 years, on ESRD due to a nephropathy of vascular or unknown origin and on dialysis or with kidney transplant, followed in one of the participating centers. Diabetic patients were eligible.

Patients fulfilling the inclusion criteria were identified using the REIN ${ }^{\circledR}$ (Renal Epidemiology Information Networks) registry and the CRISTAL ${ }^{\circledR}$ database which include all dialyzed and transplanted patients in France, respectively [14]. The REIN and the CRISTAL anonymous patient numbers were used for deidentification. The patients' nephrologist or the research technicians only had access to patient data with a confidential code. The patients' nephrologist would match the patient number to the patient, who was proposed to participate in the study. The local nephrologist was in charge of obtaining the patient consent and testing.

\section{Methods}

An enzymatic assay on dried blood spots (DBS) collected on filter paper was used for screening [13]. It was performed during a dialysis session or an outpatient transplantation follow-up visit. Nurses were trained before the procedure started. The DBS was sent (with the patient number) to the French national reference center for Fabry disease (http://centre-geneo.com) for analysis. When a patient was tested positive for FD, his nephrologist was notified by the principal investigator and confirmation genotyping was proposed. The pathogenicity of the variant was verified according to ACMG criteria [15] and in-house database [16]. Identified patients were given the option to complete the work-up recommended by the French reference center and published guidelines $[5,17,18]$. Specific therapy was then proposed and familial screening using cascade genotyping was recommended [19]. These two last steps were not part of the protocol but represent the standard of care in $\operatorname{FD~}[1,5]$.

\section{REVISED MANUSCRIPT}




\section{Results}

The extraction of the REIN and CRISTAL registries led to the identification of 1561 eligible patients, 711 on dialysis (46\%) and 850 with a kidney transplant (54\%). Between September 2016 and July 2018, 819 out of these 1561 patients (52\%) were screened with DBS: 242 on dialysis $(34 \%$ of the selected dialyzed cohort) and 577 transplanted $(68 \%$ of the selected cohort). Seven hundred and forty-two patients were not screened for various reasons: some centers refused participation to the study (156 patients); 55 patients did not fulfill the inclusion criteria, 41 patients refused to consent, 54 patients had died, and 436 patients without explanation.

According to the inclusion criteria, all patients were male. The median age was 60.0 years. Nephropathies extracted from REIN $^{\circledR}$ and CRISTAL $^{\circledR}$ registries were vascular for $32.1 \%$, diabetic for $30.2 \%$, unknown for $37.7 \%$. Study population characteristics are summarized in table 1.

Only one patient $(0.1 \%)$ had a positive DBS result (alpha-galactosidase levels $<25 \%$ of normal values) subsequently confirmed by genetic analysis, which identified a previously reported missense pathogenic variant (p.Phe113Leu or p.F113L) in exon 2 of the $G L A$ gene $[20,21]$.

The patient was a 45-year-old transplanted male. He was first seen in a division of nephrology in 1996 at 26 years of age for hypertension and two years later for proteinuria and hematuria. IgA nephropathy was suspected but kidney biopsy was never performed. He was started on hemodialysis eight years later. Pre-transplantation cardiac echography was normal. In 2007, he received renal transplantation from a living donor (his wife's kidney).

Clinical examination performed after the diagnosis of FD (2019) found no history of acroparesthesia during childhood, absence of cornea verticillata and no hypohidrosis, all hallmarks of classic Fabry disease [4, 16]. Cutaneous examination did not reveal any

\section{REVISED MANUSCRIPT}


angiokeratoma. The patient only reported moderate leg edema during childhood and one syncope during excessive stress.

The patient was started on specific therapy with the pharmacological chaperone migalastat [22]. Family screening identified a brother with low alpha-galactosidase activity, confirmed by genotyping, who also benefited from specific FD therapy.

\section{Discussion}

This screening of a large cohort of 819 male patients with ESRD in Western France led to the diagnosis of FD in one single patient, resulting in a prevalence of $0.12 \%$. This percentage is in agreement with most previous screening studies performed in ESRD patients in various countries [12]. However, these figures are half of the prevalence recently reported by a large group of Argentinian nephrologists who identified 22 cases of Fabry disease out of 9604 dialysis patients screened, all confirmed after careful analysis of GLA variants pathogenicity $[23]$.

Among the reasons which may explain the low figure found in Western France, an analytical technical issue could be hypothesized. However, this is unlikely since i) the sensitivity and specificity of our enzymatic assay has been initially validated on 209 individuals and repeatedly verified on hundreds of Fabry disease patients over the years [13] ii) we had selected the ideal population for a systematic screening based on enzymatic activity on DBS namely males with end-stage renal disease. Indeed, heterozygous females for FD can have clinical presentations ranging from asymptomatic to severely affected depending on their $\mathrm{X}$ chromosome inactivation profile [24] so that measurement of alpha-Gal A activity may be unreliable for identifying heterozygotes, since many will have subnormal enzymatic levels [5, 24]. Accordingly, female patients were not considered for this screening study based on an enzymatic assay, thereby avoiding false negative results in females.

\section{REVISED MANUSCRIPT}


Furthermore, ESRD is associated with the classic form of FD and dramatically decreased or absent alpha-galactosidase activity, making the screening with an enzymatic assay on a dried blood spot more reliable in this subset of FD patients $[13,16]$.

The upper age threshold of 70 years was proposed among exclusion criteria to avoid the numerous elderly patients with frequent cardiorenal comorbidities likely to have another origin than FD who would have further lowered the prevalence. In our experience, the reduced life expectancy associated with the various complications makes unlikely, in the absence of treatment, to have missed classic FD patients over that age.

Finally, since diabetes is common in the general population, we also chose not to consider diabetes among exclusion criteria in order not to miss possible coexistence of diabetes and FD in some patients.

Whether the differences in the percentage of eligible subjects who declined participation to the study between the two groups (transplanted versus dialyzed) may have accounted for the low prevalence is unknown. There was a higher percentage of eligible patients who declined participation among dialyzed patients (66\%) versus transplanted patients $(32 \%)$, which may have accounted for the low prevalence found in this study. However, a recent meta-analysis of all 63 studies which screened for Fabry disease in at-risk populations retrieved comparable prevalences for populations of male subjects on dialysis $(0.21 \%)$ or with kidney transplant $(0.25 \%)[12]$.

Despite the low prevalence of Fabry disease reported in this study and others [12] the value of screening protocols (in combination with subsequent family cascade genotyping) as an interesting way to diagnose rare genetic diseases should be emphasized. However, while specific alpha-galactosidase enzymatic assay were used successfully in the past [13], future studies aiming at elucidating nephropathies of unknown origin should be more global and based

\section{REVISED MANUSCRIPT}


on next generation sequencing with either panels of genes incorporating GLA or exome sequencing $[25,26]$.

One of the most interesting finding of the study is that the only patient diagnosed was by serendipity since the design of the screening should normally not have allowed it. The phenotypic heterogeneity of FD is considerable [1, 5], with two major forms, classic [27] and later-onset disease with clinical manifestations mainly confined to the heart [28]. The Leu113 allele has been recognized as the most common GLA variant identified in FD Portuguese patients and has been repeatedly disclosed in FD patients of Portuguese ancestry living in France, Italy and Switzerland [20]. Hemizygosity for the GLA Leu113 allele is associated with a late-onset form of FD, invariably presenting with cardiac involvement. Cerebrovascular and kidney involvement has also occasionally been reported in some patients $[20,21]$ but the pathogenic relationship between the incomplete $\alpha$-galactosidase deficiency and the risks of stroke and of chronic kidney disease is not straightforward [20]. Indeed, the etiologic interpretation of the cerebrovascular and renal complications observed in a few of those patients, and their imputation to FD, is often confounded by the coexistence of major additional risk factors [20], including long-standing severe and/or inadequately controlled hypertension, type 2 diabetes mellitus, obesity, hyperlipidemia, and tobacco smoking. Interestingly, the identified patient had initially presented with hematuria which is an uncommon finding in males with FD nephropathy $[1,5,20]$. The diagnosis of IgA nephropathy had been considered at the time of first presentation twenty years ago but never confirmed since kidney biopsy was not performed. The association between FD and IgA nephropathy has been reported in a number of cases and is one argument in favor of renal biopsy when the phenotype does not match the predictions from the genotype $[29,30]$. In the present study, the absence of renal biopsy and histopathology data prevented us to definitely conclude between a coincidental diagnosis through screening for low plasma alpha-galactosidase in a later-onset cardiac variant of FD in 
a patient with IgA nephropathy-related ESRD and the rare occurrence (7\%) of renal disease in association with the GLA Leu113 variant [21].

Given the high morbidity of FD, initiation of specific therapy will likely be of benefit for the index case and his brother identified through family screening [19]. However, long term positive outcomes of specific therapy have only been reported for enzyme replacement therapy and in case of its early initiation $[31,32]$. The chaperone therapeutic option which has been opted for in this study warrants careful evaluation of its therapeutic outcomes. Of note, the follow-up of the kidney function, while being unsuitable in this patient on dialysis, would also not be the appropriate outcome measure in FD patients bearing a GLA variant associated with the later-onset form of FD since no major renal deterioration is to be expected in those individuals [28]. The later aspect is very important to consider in order not to unduly claim for benefits of a therapeutic intervention in terms of renal function in such patients [33].

From an epidemiological point of view, the study protocol raised the question of its efficiency with only one case identified through the screening of 819 patients, after an important administrative workload and the need for training all participating nurses. The rapid progress in NGS technologies advocates to consider gene panels or exome sequencing in clinical practice to diagnose nephropathies of unknown origin especially since the cost should decrease with time. Screening protocols should now implement NGS approaches and be combined with the search for other inherited kidney diseases using gene panels rather than focusing on a single disease, in order to increase the diagnostic yield of these screening studies. In a recent publication, exome sequencing in a cohort of 3315 patients with chronic kidney disease resulted in a diagnostic yield of 9.3\% among which 3 cases of FD [26]. Panels of genes and exome sequencing likely represent the future of screening approaches in patients with unexplained ESRD $[19,25,26,34]$. However, this approach needs to be validated especially with respect to interpretation of variants of unknown significance [34, 35].

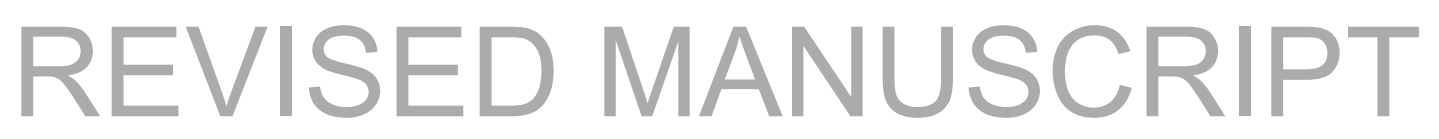




\section{Conclusion}

A large screening using enzymatic assay on dried blood spots in 819 male patients with ESRD in Western France identified one single patient with FD, corresponding to an estimated prevalence of $0.12 \%$. Subsequent cascade genotyping identified an affected brother leading to initiation of disease specific therapy in those two male patients. Whether it is worth to screen over 800 patients to identify 2 cases is debatable. In view of the complexity of such a large study, this strategy does not appear very efficient. However, an unexpected benefit was that it raised the awareness of FD among the participating nephrologists, increasing their knowledge of this rare, underdiagnosed, treatable metabolic disease. This may lead to earlier diagnosis and treatment of patients with FD by those health care professionals in the future. NGS technologies allowing the screening for FD together with the study of other genes will increase the diagnostic yield of screening protocols in patients with nephropathies of unknown origin.

\section{Acknowledgments}

The authors thank all nephrologists from the Société de Néphrologie de l'Ouest (SNO) for their active participation as investigators in this study.

The list of investigators is available at:

https://docs.google.com/spreadsheets/d/1hE_dzDgpxlXzVPtjHVkkSRssC6laRljCgK5mLYdZ $\underline{\mathrm{x}-4 / \mathrm{edit} \text { ?usp }=\text { sharing }}$

We also acknowledge the technical expertise of Mrs Sylvie Le Stum (Rennes) and Coralie Favier (Garches) as study coordinators.

Funding for this Investigator Sponsored Study was provided by Sanofi Genzyme. The sponsor had no role in the design or writing of the manuscript. 


\section{CRediT author statement}

Cecile Vigneau: Conceptualization, methodology, investigation and writing. Dominique P.

Germain: Investigation, writing, reviewing and editing. David Larmet: Investigation and data curation. Firas Jabbour: Investigation. Maryvonne Hourmant: Conceptualization, methodology, investigation, and writing.

All authors read and approved the final manuscript. 
Table 1: Patient's characteristics at screening and study results

\begin{tabular}{|l|l|l|l|}
\hline & Transplanted & Dialyzed & Total \\
\hline Number & 850 & 711 & 1561 \\
\hline Median age/mean age & $57.5 / 54.9(11.1)$ & $62.9 / 59.2(10.6)$ & $60.0 / 56.9(11.2)$ \\
(Standard deviation) & Nephropathy & $265(37,3 \%)$ & $501(32,1 \%)$ \\
Vascular/Hypertensive & $236(27,8 \%)$ & $221(31,1 \%)$ & $471(30,2 \%)$ \\
Unknown & $250(29,4 \%)$ & $225(31,6 \%)$ & $589(37,7 \%)$ \\
\hline DBS result & $364(42,8 \%)$ & 0 & 1 \\
Positive & 1 & 242 & 818 \\
\hline Negative & 576 & & \\
\hline
\end{tabular}

\section{Legends to Figures}

Figure 1: Number of dialysis and transplanted patients screened per region of Western France. 


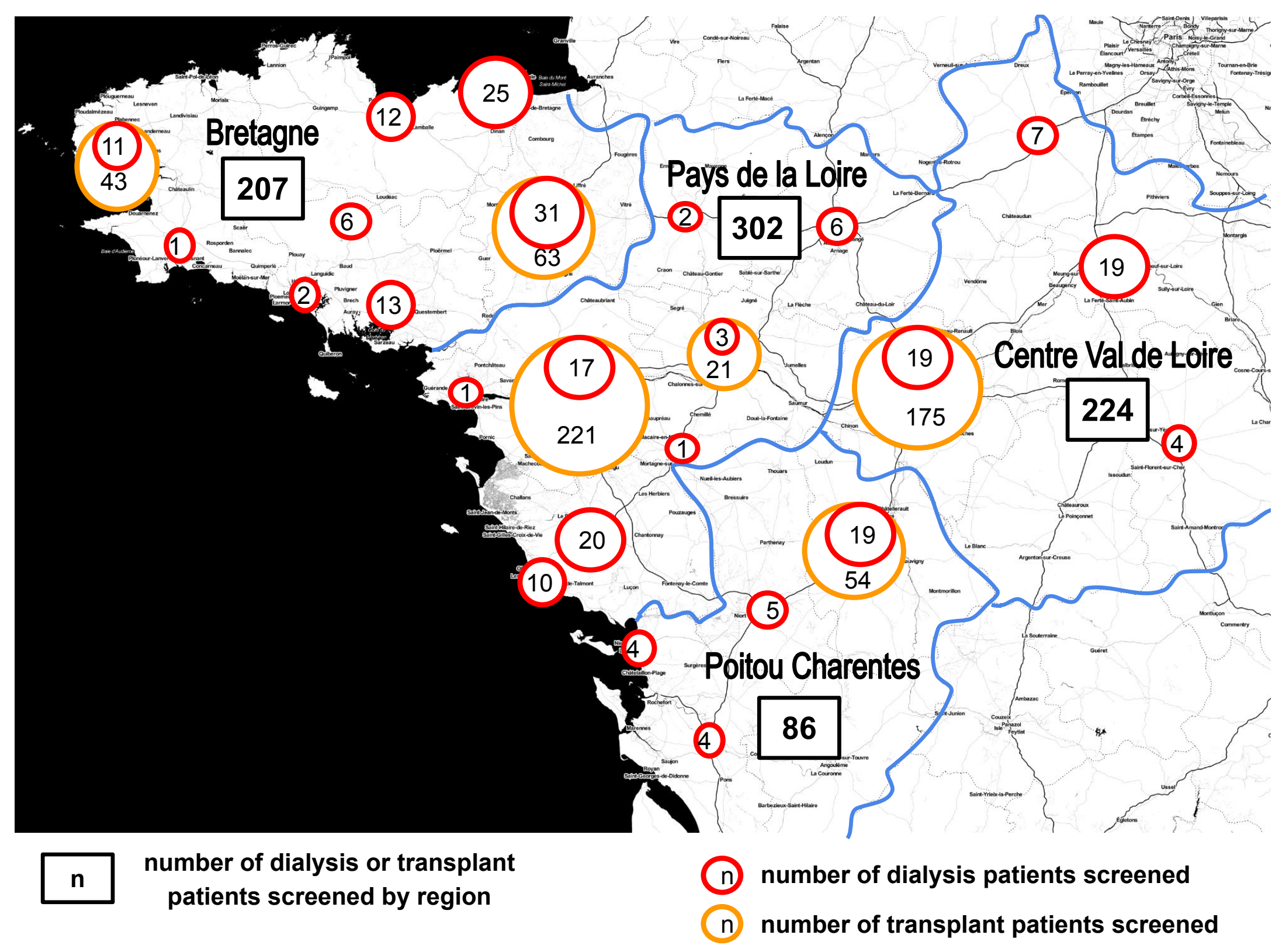




\section{REFERENCES}

1. Germain DP. Fabry disease. Orphanet J Rare Dis 2010; $5: 30$.

2. Germain DP, Biasotto M, Tosi M, Meo T, Kahn A, Poenaru L. Fluorescence-assisted mismatch analysis (FAMA) for exhaustive screening of the alpha-galactosidase A gene and detection of carriers in Fabry disease. Hum Genet 1996; 98: 719-726.

3. Germain DP, Poenaru L. Fabry disease: identification of novel alpha-galactosidase A mutations and molecular carrier detection by use of fluorescent chemical cleavage of mismatches. Biochem Biophys Res Commun 1999; 257: 708-713.

4. Auray-Blais C, Blais CM, Ramaswami U, Boutin M, Germain DP, Dyack S et al. Urinary biomarker investigation in children with Fabry disease using tandem mass spectrometry. Clin Chim Acta 2015; 438:195-204.

5. Ortiz AO, Germain DP, Desnick RJ, Politei J, Mauer M, Burlina A et al. Fabry disease revisited: management and treatment recommendations for adult patients. Mol Genet Metab 2018; 123: 416-427.

6. Linhart A, Germain DP, Olivotto I, Akhtar MM, Anastasakis A, Hughes D et al. An expert consensus document on the management of cardiovascular manifestations of Fabry disease. Eur J Heart Fail 2020; 22: 1076-1096.

7. Kolodny E, Fellgiebel A, Hilz MJ, Sims K, Caruso P, Phan TG et al. Cerebrovascular involvement in Fabry disease: current status of knowledge. Stroke 2015; 46: 302-313.

8. Spada M, Pagliardini S, Yasuda M, Tukel T, Thiagarajan G, Sakuraba H et al. High incidence of later-onset fabry disease revealed by newborn screening. Am J Hum Genet. 2006; 79: 31-40. 
9. Hwu WL, Chien YH, Lee NC, Chiang SC, Dobrovolny R, Huang AC et al. Newborn screening for Fabry disease in Taiwan reveals a high incidence of the later-onset GLA mutation c.936+919G>A (IVS4+919G>A). Hum Mutat 2009; 30: 1397-1405.

10. Nakao S, Kodama C, Takenaka T, Tanaka A, Yasumoto Y, Yoshida A, et al. Fabry disease: detection of undiagnosed hemodialysis patients and identification of a "renal variant" phenotype. Kidney Int 2003; 63: 801-807.

11. Linthorst GE, Bouwman MG, Wijburg FA, Aerts JM, Poorthuis BJ, Hollak CE. Screening for Fabry disease in high-risk populations: a systematic review. J Med Genet. 2010 Apr;47(4):217-22

12. Doheny D, Srinivasan R, Pagant S, Chen B, Yasuda M, Desnick RJ. Fabry Disease: prevalence of affected males and heterozygotes with pathogenic GLA mutations identified by screening renal, cardiac and stroke clinics, 1995-2017. J Med Genet. 2018; 55: $261-268$.

13. Caudron E, Prognon P, Germain DP. Enzymatic diagnosis of Fabry disease using a fluorometric assay on dried blood spots: An alternative methodology. Eur J Med Genet 2015; 58: 681-684.

14. Vigneau C, Kolko A, Stengel B, Jacquelinet C, Landais P, Rieu P et al. REIN Registry. Ten-years trends in renal replacement therapy for end-stage renal disease in mainland France: Lessons from the French Renal Epidemiology and Information Network (REIN) registry. Nephrol Ther. 2017; 13: 228-235.

15. Richards S, Aziz N, Bale S, Bick D, Das S, Gastier-Foster J et al. Standards and guidelines for the interpretation of sequence variants: a joint consensus recommendation of the American College of Medical Genetics and Genomics and the Association for Molecular Pathology. Genet Med 2015; 17: 405-424.

\section{REVISED MANUSCRIPT}


16. Germain DP, Oliveira JP, Bichet DG, Yoo HW, Hopkin RJ, Lemay R et al. Use of a rare disease registry for establishing phenotypic classification of previously unassigned $G L A$ variants: a consensus classification system by a multispecialty Fabry disease genotype-phenotype workgroup. J Med Genet 2020; 57: 542-551.

17. Wanner C, Arad M, Baron R, Burlina A, Elliott PM, Feldt-Rasmussen U et al. European Expert Consensus statement on therapeutic goals in Fabry disease. Mol Genet Metab 2018; 124: 189-203.

18. Hagège A, Réant P, Habib G, Damy T, Barone-Rochette G, Soulat G et al. Fabry disease in cardiology practice: literature review and expert point of view. Arch Cardiovasc Dis 2019; 112: 278-287.

19. Germain DP, Moiseev S, Suárez-Obando F, Al Ismaili F, Al Khawaja H, Altarescu G et al. The benefits and challenges of family genetic testing in rare genetic diseases lessons from Fabry disease. Mol Genet Genome Med 2021; in press.

20. Oliveira JP, Nowak A, Barbey F, Torres M, Nunes JP, Teixeira-E-Costa F et al. Fabry disease caused by the GLA p.Phe113Leu (p.F113L) variant: Natural history in males. Eur J Med Genet 2020, 63(2): 103703.

21. Azevedo O, Gal A, Faria R, Gaspar P, Miltenberger-Miltenyi G, Gago MF et al. Founder effect of Fabry disease due to p.F113L mutation: Clinical profile of a late-onset phenotype. Mol Genet Metab 2020, 129: 150-160.

22. Germain DP, Hughes DA, Nicholls K, Bichet DG, Giugliani R, Wilcox WR et al. Treatment of Fabry's disease with the pharmacologic chaperon migalastat. N Engl J Med 2016; 375: 545-555.

23. Frabasil J, Durand C, Sokn S, Gaggioli D, Carozza P, Carabajal R et al. Prevalence of Fabry disease in male dialysis patients: Argentinean screening study. JIMD Report 2019; 48: 45-52. 
24. Echevarria L, Benistan K, Toussaint A, Dubourg O, Hagege AA, Eladari D et al. Xchromosome inactivation in female patients with Fabry disease. Clin Genet. 2016; 89: 44-54.

25. Ortiz A, Cianciaruso B, Cizmarik M, Germain DP, Mignani R, Oliveira JP et al. Endstage renal disease in patients with Fabry disease: natural history data from the Fabry Registry. Nephrol Dial Transplant $2010 ; 25$ : 769-775.

26. de Haan A, Eijgelsheim M, Vogt L, Knoers NVAM, de Borst MH. Diagnostic yield of next-generation sequencing in patients with chronic kidney disease of unknown etiology. Front Genet. 2019; 10: 1264.

27. Groopman EE, Marasa M, Cameron-Christie S, Petrovski S, Aggarwal VS, MiloRasouly H et al. Diagnostic Utility of Exome Sequencing for Kidney Disease. N Engl J Med. 2019; 380: 142-151.

28. Germain DP, Brand E, Burlina A, Cecchi F, Garman SC, Kempf J et al. Phenotypic characteristics of the p.Asn215Ser (p.N215S) GLA mutation in male and female patients with Fabry disease: A multicenter Fabry Registry study. Mol Genet Genomic Med 2018; 6: $492-503$.

29. Whybra C, Schwarting A, Kriegsmann J, Gal A, Mengel E, Kampmann C et al. IgA nephropathy in two adolescent sisters heterozygous for Fabry disease. Pediatr Nephrol. 2006; 21: 1251-1256.

30. Yang $\mathrm{N}$, Wang $\mathrm{X}, \mathrm{Xu} \mathrm{F}$, Zeng $\mathrm{C}$, Wang J, Liu Z. Clinical and pathological characteristics of Fabry disease combined with IgA nephropathy in Chinese patients. Clin Nephrol. 2017; 87: 188-195.

31. Germain DP, Elliott PM, Falissard B, Fomin VV, Hilz MJ, Jovanovic A et al. The effect of enzyme replacement therapy on clinical outcomes in male patients with Fabry 
disease: A systematic literature review by a European panel of experts. Mol Genet Metab Rep. 2019; 19: 100454.

32. Germain DP, Arad M, Burlina A, Elliott PM, Falissard B, Feldt-Rasmussen U et al. The effect of enzyme replacement therapy on clinical outcomes in female patients with Fabry disease - A systematic literature review by a European panel of experts. Mol Genet Metab 2018; 126; 224-235.

33. Lenders M, Nordbeck P, Kurschat C, Karabul N, Kaufeld J, Hennermann JB et al. Treatment of Fabry's disease with migalastat: outcome from a prospective observational multicenter study (FAMOUS). Clin Pharmacol Ther 2020; 108: 326-337.

34. Germain DP, Jurca-Simina I. Principle of Human Genetics and Mendelian Inheritance In: Burlina AP, ed. Neurometabolic Hereditary Diseases of Adults. Springer 2018:1-28.

35. Friedman JM, Lyons Jones K, Carey JC. Exome sequencing and clinical diagnosis. JAMA 2020; 324: 627-628. 